\title{
Reactive Astrogliosis in the Neonatal Mouse Brain and Its Modulation by Cytokines
}

\author{
Vijayabalan Balasingam, Trevor Tejada-Berges, Erin Wright, Radka Bouckova, and Voon Wee Yong \\ Montreal Neurological Institute, Department of Neurology and Neurosurgery, McGill University, Montreal, Quebec H3A \\ 2B4, Canada
}

\begin{abstract}
Reactive astrogliosis is a characteristic response of astrocytes to inflammation and trauma of the adult CNS. To assess the hypothesis that cytokines from inflammatory mononuclear cells that accumulate around lesion sites have a role in modulating astrogliosis, this study sought to take advantage of the neonatal system in which astrogliosis is reported to be minimal following injury and in which the immune system is relatively immature compared to adult animals. A nitrocellulose membrane implant into the cortex of postnatal day 3 mice resulted in a tremendous astrogliotic response $4 \mathrm{~d}$ later, as measured by glial fibrillary acidic protein (GFAP) immunoreactivity and GFAP content. In contrast, a neonatal stab wound produced limited astroglial response when compared to the adult stab wound. Utilizing the neonatal stab wound model, cytokines were microinjected into the wound site at the time of injury. All cytokines tested ( $\gamma-$ IFN, IL-1, IL-2, IL-6, TNF- $\alpha$, and M-CSF) resulted in a significantly increased astrogliosis. The specificity of the cytokine response was demonstrated by the inability of human $\gamma$-IFN, but not mouse $\gamma$-IFN, in enhancing neonatal mouse astrogliosis, in accordance with reports that the interaction of $\gamma$-IFN with its receptor occurs in a species-specific manner. We conclude that neonatal astrocytes can become reactive if an adequate injury stimulus is presented, and that the release of immunoregulatory cytokines by cells around lesion sites may be a mechanism that contributes to the production of gliosis.
\end{abstract}

[Key words: astrogliosis, cytokine, gliosis, interferon, glial fibrillary acidic protein, neonates]

Reactive astrogliosis, where astrocytes undergo hypertrophy and/ or proliferation in addition to other histological and enzymatic changes, is a prominent aftermath following trauma and inflammation to the CNS (Latov et al., 1979; Smith et al., 1983; Mathewson and Berry, 1985; Maxwell et al., 1990a,b). A longterm result of the astrocytic reaction can be the formation of a glial scar at the lesion site (Reier et al., 1983; Liuzzi and Lasek,

Received Apr; 26, 1993; revised Aug. 4, 1993; accepted Aug. 11, 1993.

This work was supported by the Medical Research Council of Canada. V.B. is the recipient of a studentship from the Canadian network for neural regeneration and functional recovery, one of 15 networks of Centres of Excellence supported by the Government of Canada. We thank Dr. Larry Eng for introducing us to the technique for measuring the content of GFAP, and Ms. Jolanda Turley for skilled technical assistance.

Correspondence should be addressed to Voon Wee Yong, Ph.D., Montreal Neurological Institute, 3801 University Street, Montreal, Quebec H3A 2B4, Canada.

Copyright (C) 1994 Society for Neuroscience $0270-6474 / 94 / 140846-11 \$ 05.00 / 0$
1987), which, via yet poorly understood mechanisms, may inhibit axonal regeneration or remyelination.

Injury to the CNS also involves the recruitment of both endogenous and exogenous inflammatory mononuclear cells, particularly when the blood-brain barrier is breached (Kitamura et al., 1972; Tsuchihashi et al., 1981; Giulian, 1987; Giulian et al., 1989; Morshead and van der Kooy, 1990; Milligan et al., 1991; Woodroofe et al., 1991; Taupin et al., 1993). The cytokines released by the inflammatory mononuclear cells may have a role in modulating astrogliosis. This notion is supported by studies where the administration of interleukin-1 (IL-1) (Giulian et al., 1988), interleukin-2 (IL-2) (Watts et al., 1989), and interferon- $\gamma(\gamma$-IFN) (Yong et al., 1991a) into the adult rodent brain increases the extent of glial fibrillary acidic protein immunoreactivity (GFAP-IR). Intraocular injections of $\gamma$-IFN, tumor necrosis factor- $\alpha$ (TNF- $\alpha$ ), and IL- 1 have also been reported to evoke gliosis in rabbits (Brosnan et al., 1989). In addition, in vitro evidence for the proliferation of neonatal rat or calf bovine astrocytes in response to IL-1, IL-6, and TNF- $\alpha$ (Giulian and Lachman, 1985; Nieto-Sampedro and Berman, 1987; Selmaj et al., 1990), and human astrocytic cell lines or primary human astrocytes to TNF- $\alpha$ and $\gamma$-IFN (Barna et al., 1990; Yong et al., 1991a, 1992) have given further credence to the direct or indirect role of cytokines in promoting astroglial reactivity.

While the presentation of astrogliosis is common to injuries occurring in the adult CNS, injuries inflicted during embryonic or neonatal periods have been observed to produce minimal astrogliosis, if any at all, in cortical stab wounds (Sumi and Hager, 1968; Bignami and Dahl, 1976; Berry et al., 1983; Maxwell et al., 1990b) and spinal cord lesions (Osterberg and Wattenberg, 1963; Gearhart et al., 1979; Bernstein et al., 1981; Barrett at al., 1984), although this contention has been challenged (Roessmann and Gambetti, 1986; Moore et al., 1987; Trimmer and Wunderlich, 1990). Reasons postulated for the lack of astrogliosis in neonatal CNS injuries have included the relative immaturity and plasticity of neonatal astrocytes and neurons, and the lack of myelin in neonatal animals. Since the immune system in neonatal animals is relativcly immature compared to adults (Hobbs, 1969; Abo et al., 1983; Lu and Unanue, 1985; De Paoli et al., 1988; Hannet et al., 1992), the consequent lack of cytokine production to evoke astrogliosis may constitute a probable cause of the lack of astrogliosis following neonata! CNS injuries. To explore this postulate, the aim of the present study was to inflict damage to the neonatal brain, to document the resultant extent of astrogliosis, and to determine whether this extent could be increased by exogenously administered cytokines.

Initial studies using the implantation of a piece of nitrocel- 
lulose membrane (NC) into the cerebral cortex of postnatal day 3 (P3) mouse resulted in extensive GFAP-IR and increased GFAP content when measured $4 \mathrm{~d}$ postinjury. In contrast, a neonatal stab wound resulted in minimal astrogliosis, in accordance with the multitude of reports that have documented minimal astrogliosis in neonatal animals following a stab injury (Sumi and Hager, 1968; Bignami and Dahl, 1976; Berry et al., 1983; Maxwell et al., 1990b) compared to an adult stab wound (Cavanagh, 1970; Mathewson and Berry, 1985; Hozumi et al., 1990; Maxwell et al., 1990a).

Using the neonatal stab wound model, with its minimal astrogliosis, a bolus dose of cytokines $(20 \mathrm{U}$ in $2 \mu \mathrm{l})$ was administered to the stab cavity immediately following the injury. We demonstrate that while controls had minimal astrogliosis $4 \mathrm{~d}$ after, cytokine-treated animals had extensive astrogliosis. All cytokines tested $[\gamma-$ IFN, IL-1, IL-2, IL- 6, TNF- $\alpha$, and human macrophage colony-stimulating factor (M-CSF)] provided for enhanced astrogliosis as determined by GFAP-IR. The species specificity of the cytokine effect was demonstrated by the inability of human $\gamma$-IFN to evoke a gliotic response in accordance with reports that the interaction of $\gamma$-IFN with its receptor occurs in a species-specific manner (Gray et al., 1989; Hemmi et al., 1989; Rubio and de Felipe, 1991; Plata-Salaman, 1992). The results suggest that the occurrence of astrogliosis in neonatal animals is dependent on the type of injury inflicted, and that the release of immunoregulatory cytokines by cells around lesion sites could be a mechanism that contributes to the production of astrogliosis.

\section{Materials and Methods}

Creation of brain injury in neonatal mouse. Postnatal day $3 \mathrm{CD} 1$ mouse pups (of either sex from standard-sized litters) obtained from a commercial source (Charles River Canada, Montreal, Canada) were anesthetized with inhalational methoxyflurane. An incision was made in the skin overlying the skull, and an iris scissors was used to make a $1 \mathrm{~mm}$ cut in the skull. Three different types of injuries were then inflicted in groups of animals. For $N C$ stab injury, a dry $1 \mathrm{~mm}^{2}$ piece of nitrocellulose membrane (Schleicher and Schuell, Keene, $\mathrm{NH}$ ) previously boiled in three changes of water to remove surfactant (Rudge et al,, 1989) was inserted into the parietal cortex perpendicular to the surface and removed immediately. For $N C$ implant injury, animals were treated in the same manner but the membrane was left in place for the entire duration of the experiment (4 d). For scissors stab animals, an iris scissors was used to make a 1-mm-deep cut to the parietal cortex. The incision was closed using Krazy Glue and the pups were kept under a heat lamp for $1 \mathrm{hr}$ before being returned to their nursing mothers.

Creation of scissors stab injury in adult mouse brains. Female CD1 retired breeders (Charles River Canada, Montreal, Canada) were anesthetized with an intraperitoneal injection of chloral hydrate $(150 \mathrm{mg}$ / $\mathrm{kg}$ ) and immobilized in a stercotaxic framc. A midlinc incision was made and a unilateral circular (2-mm-diameter) craniectomy was performed over the left hemisphere by using a dental drill. The scissors stab injury was inflicted as described for neonates and the animals were kept under a heat lamp for $1 \mathrm{hr}$ postsurgery.

Administration of cytokines to neonatal animals in vivo. Immediately following the scissors stab injury, a 22 gauge Hamilton microinjector (Hamilton Company, Reno, NV) attached to a stereotaxis instrument was used to deposit $2 \mu \mathrm{l}$ of recombinant cytokine solution $(10 \mathrm{U} / \mu \mathrm{l})$ directly to the wound site. Injection rate was $1 \mu \mathrm{l} / \mathrm{min}$. The skin incision was closed with Krazy Glue as above. The following recombinant cytokines suspended in $0.2 \%$ BSA were utilized: murine $\gamma$-IFN, human $\gamma$-IFN, human IL-1 $(\alpha, \beta)$, human IL-2, human IL-6, human tumor necrosis factor- $\alpha$ (TNF- $\alpha$ ) and human macrophage colony-stimulating factor (M-CSF). These were chosen to reflect cytokines predominantly released by T-lymphocytes ( $\gamma$-IFN, IL-2, and M-CSF) or microglia/ macrophages (IL-1, IL-6, TNF- $\alpha$ ) that are likely to be present at lesion sites, although astroglia have the potential to make some of these cytokines under selective conditions (Wesselingh et al., 1990). Except for
$\gamma$-IFN, all the human cytokines used are described to be effectivc on murine cells by the manufacturers (Genzyme, Cambridge, MA; United Biotechnology Inc., Lake Placid, NY).

Qualitative and quantitative assessment of GFAP-IR in situ. All animals were killed by $\mathrm{CO}_{2}$ asphyxiation $4 \mathrm{~d}$ following surgery; this time point was chosen to reflect our findings (Moumdjian et al., 1991; Yong et al., 1991a) and those of others (Norton et al., 1992) that the extent of GFAP-IR is likely to be extensive at this juncture, at least in adult stab injuries. Brain was removed and quick-frozen in isopentane on dry ice. Ten micrometer coronal sections were obtained on gelatin-coated slides and subjected to immunofluorescence for GFAP (glial fibrillary acidic protein), a cytoplasmic intermediate filament specific for astrocytes (Eng, 1985). In brief, sections were air dried for $10 \mathrm{~min}$ and fixed in $70 \%$ ethanol for $20 \mathrm{~min}$. After washing with phosphate-buffered saline (PBS), each section was treated for $2 \mathrm{hr}$ with $3 \%$ ovalbumin (Sigma) as a blocking step prior to incubation with a rabbit anti-GFAP polyclonal antibody (1:100; Dako Corp.) for $6 \mathrm{hr}$ at room temperature. Following a brief rinse with PBS, a goat anti-rabbit immunoglobulin conjugated to FITC (1:75; Jackson) was introduced for $1 \mathrm{hr}$. Negative control for immunohistochemistry was replacement of the primary antibody with the diluting medium for antibody, HHG (1 mM HEPES buffer, $2 \%$ horse serum, $10 \%$ goat serum in Hanks' balanced salt solution). This was followed by a brief rinse in PBS and a final water rinse before mounting with Gelvatol. Slides were coded so that the qualitative assessment of GFAP-IR could be performed blind. Examination was restricted to the cortical regions, since astrocytes in these areas, unlike those in the external glia limitans and corpus callosum, are normally not GFAP-IR although containing this intermediate-filament protein (Bignami and Dahl, 1974). The arca of the cortex containing GFAP-IR astrocytes was qualitatively tabulated from + to ++++ in ascending order of cortical area covered by GFAP-IR astrocytes.

Quantitative assessment of GFAP-IR for the different injury models was performed using a confocal laser scanning microscope (Leica Lasertechnik, Heidelberg, Germany) following immunolabeling for GFAP. Only the dorsal cortex ipsilateral to the lesion site and its corresponding contralateral area were scanned for the quantitative assessment. The scanner was mounted on a Leica Fluovert FS Microscope and optical excitation was achieved on the $488 \mathrm{~nm}$ line of an argon laser. The emitted fluorescent light was directed through a band-pass filter peaking at $535 \pm 7 \mathrm{~nm}$ before transmission to the photomultiplier. Samples were scanned with a $2.5 \times, 0.08 \mathrm{NA}$ objective in order to encompass the cortical ipsilateral hemisphere within the laser's image acquisition domain. The image was rcconstructed from the averages of 64 passes per raster line (scan -64), in an attempt to obtain high signal-to-noise ratio. The same area of cortex (at lesion site) was examined in all animals, the criteria being the density of GFAP-IR cells and the degree of spread of reactivity as one moved away from the wound site. Areas with GFAP-IR were traced out on each section to encompass only regions contributing to a cumulative immunofluorescence intensity with a standard deviation of 30 . This criterion was adopted to achieve uniform conservative estimates on the extent of astrogliosis in all groups except the scissors stab and NC stab animals. For the latter samples, the relatively small GFAP-IR cortical areas necessitated scanning using a $10 \times, 0.30 \mathrm{NA}$ objective in order to facilitate image acquisition. Images were also obtained (at scan -8 ) with a $40 \times, 1.3 \mathrm{NA}$ oil immersion objective for all groups, as a means to verify the presence of GFAP-IR astrocytcs in all samples scanned with a lower-powered objective.

Quantification of GFAP content. GFAP protein extraction and analysis by sodium dodecyl sulfate-polyacrylamide gel electrophoresis (SDSPAGE) were carried out via a modified protocol as previously described (Hozumi et al., 1990). Cortical lesion site was resected $4 \mathrm{~d}$ following injury and quick-frozen on dry ice. In addition, areas corresponding to the lesion site on the contralateral side as well as areas ipsilaterally anterior to the lesion site were also resected. Pooled resected cortical tissue from uninjured normal animals served as controls. Each sample (approximately $10 \mathrm{mg}$ ) was homogenized in $50 \mathrm{vol}$ of $100 \mathrm{~mm}$ phosphate buffer ( $\mathrm{pH} 7.4)$ containing $8 \mathrm{M}$ urea at $4^{\circ} \mathrm{C}$. The homogenate was boiled for $5 \mathrm{~min}$ on a heat block at $100^{\circ} \mathrm{C}$ and then analyzed for total protein content with a protein assay kit (Bio-Rad) that utilized bovine serum albumin as a standard. Six milligrams of protein extract were further diluted in sample buffer $(50 \mathrm{~mm}$ Tris- $\mathrm{HCl}$ (pH 6.8), $2 \% \mathrm{SDS}, 10 \%$ glycerol, $\sim 0.1-0.05 \%$ bromophenol blue) and boiled for $5 \mathrm{~min}$ at $100^{\circ} \mathrm{C}$. Samples (in $20 \mu \mathrm{l} \mathrm{vol}$ ) were electrophoresed on a 10\% SDS-PAGE for $45 \mathrm{~min}$ at $200 \mathrm{~V}$ constant voltage, with different quantities of purified bovine GFAP (Boehringer-Mannheim) as standards. 


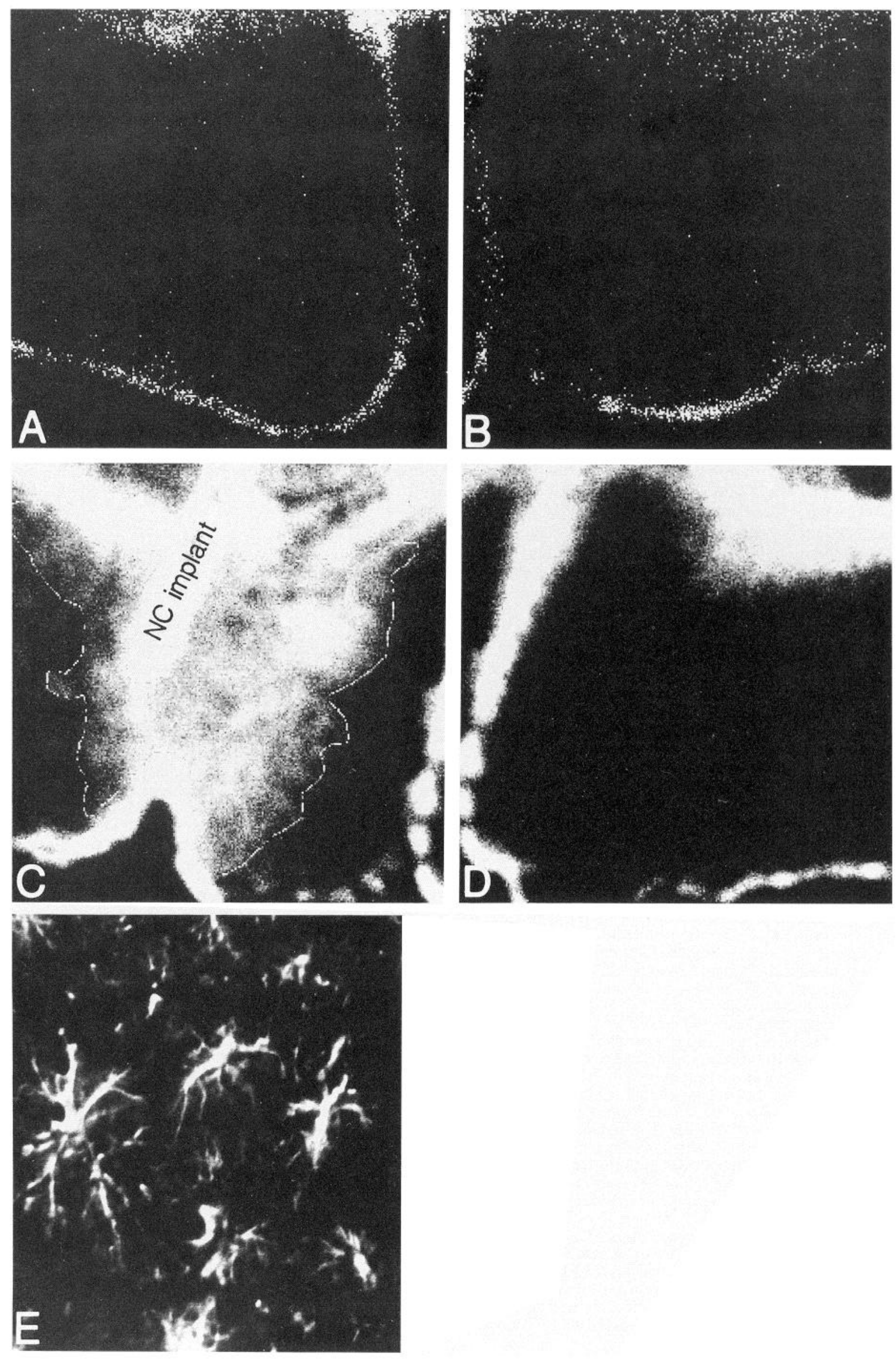


After electrophoresis, the samples were transblotted to a piece of Immobilon $\mathrm{P}$ membrane (Millipore) at $100 \mathrm{~V}$ constant voltage for $1 \mathrm{hr}$ at $4^{\circ} \mathrm{C}$. The membrane was incubated in $5 \%$ skim milk in PBS (Blotto) followed by anti-GFAP antibody solution (Dako; diluted 1:1000 in Blotto) for $2 \mathrm{hr}$ at $4^{\circ} \mathrm{C}$. The membrane was rinsed in PBS and incubated in ${ }^{125}$ I-Protein $\mathrm{A}(2 \mu \mathrm{Ci}$ diluted in $20 \mathrm{ml}$ of Blotto $)$ for $1 \mathrm{hr}$. GFAP protein content was quantified on a phosphor-imager (Molecular Dynamics) using IMAGE QUANT software. For each membrane, the concentration of GFAP in each sample was determined by comparison to a standard curve constructed from the integrated volumes occupicd by the different purified bovine GFAP standards. The correlation coefficient for the standard curves was always 0.98 or better. To allow for comparisons between different membranes, and because several initial Western blots on the same samples showed good reproducibility, GFAP content of test samples was expressed as a ratio of GFAP content from the pooled normal cortices on the same SDS-PAGE. Representative autoradiograms of Western blots have been included (see Figs. 4, 6).

Assessment of in vitro astrocyte proliferation. The procedure for the culture of neonatal astrocytes from postnatal day 1 CD1 pups, and assessment of proliferation have been described in detail elsewhere (Yong, 1992). In all experiments, cells were treated once with test agents (see Table 3) and maintained for $4 \mathrm{~d} ; 1 \mu \mathrm{Ci}$ of ${ }^{3} \mathrm{H}$-thymidine was administered during the last $16 \mathrm{hr}$ of the experiment.

\section{Results}

Astrogliosis can occur after neonatal injury

We confined our inspection of astrogliosis to the cortical regions since the cortex of normal animals show no GFAP-IR astrocytes (Fig. 1) although containing this intermediate filament protein; in contrast, normal brains demonstrate GFAP staining of the corpus callosum and the glia limitans (Bignami and Dahl, 1974). Initial experiments using a piece of $\mathrm{NC}$ inserted into the cortex of nconatal mousc for $4 \mathrm{~d}$ ( $\mathrm{NC}$ implant) evoked extensive astrogliosis as determined by the area of GFAP-IR (Figs. 1, 3). To reconcile this observation with the multitude of reports that have documented minimal astrogliosis in neonatal animals following a CNS stab injury (Osterberg and Wattenberg, 1963; Sumi and Hager, 1968; Bignami and Dahl, 1976; Gearhart et al., 1979; Bernstein et al., 1981; Berry et al., 1983; Barrett at al., 1984; Maxwell el al., 1990b), we performed a scissors stab injury to the cortex in P3 mice. Four days later, GFAP-IR was minimal (Fig. 2); in contrast, a similar scissors stab injury to the adult mouse brain (Fig. 2) resulted in extensive gliosis with a spatial distribution described by Mathewson and Berry (1985). Furthermore, in neonatal animals stabbed with a piece of $\mathrm{NC}$ membrane that was then removed ( $\mathrm{NC}$ stab), GFAP-IR was also minimal (Fig. 2), suggesting that the increase in the GFAPIR observed in neonatal NC implant group was likely a factor of the duration of the $\mathrm{NC}$ implant in vivo.

We quantitated the area of the cortex containing GFAP-IR astrocytes in the different injury models. Figure 3 confirms the extensive increase in GFAP-IR in the neonatal NC implant group, and the minimal astrogliosis following scissors stab or NC stab to the P3 pups. Similar quantitation for adult scissors stab injury indicates that the extent of gliosis in neonatal NC implant animals was even higher than that following adult scissors stab injury (Fig. 3).

Protein extracts from the resected areas circumscribing the
Table 1. Astrologliosis in neonatal NC implant injury

\begin{tabular}{lcl} 
Injury & $\begin{array}{l}\text { Area of GFAP-IR } \\
\left(\times 10^{3} \mu \mathrm{m}^{2}\right)\end{array}$ & $\begin{array}{l}\text { GFAP content } \\
\text { (ratio of } \\
\text { normal) }\end{array}$ \\
\hline Neonatal scissors stab & $30 \pm 2(14)$ & $1.3 \pm 0.1(8)$ \\
Neonatal NC stab & $53 \pm 5(14)$ & $1.6 \pm 0.2(6)$ \\
Neonatal NC implant & $1016 \pm 37(14)^{*}$ & $3.0 \pm 0.3(13)^{*}$ \\
Adult scissors stab & $496 \pm 22(14)^{*}$ & Not done
\end{tabular}

Values are mean \pm SEM with number of samples shown in parentheses. Two brain sections per animal were scanned to give the area of GFAP-IR. For measurements of GFAP content, a $10 \mathrm{mg}$ piece of tissue circumscribing the lesion site was used per animal.

${ }^{*} p<0.05$ compared to all the other groups, using one-way ANOVA with Duncan's multiple comparisons.

lesion sites were electrophoresed on SDS-PAGE (Fig. 4). GFAP content (expressed as micrograms GFAP/mg total protein) at the lesion site was significantly increased in the neonatal $\mathrm{NC}$ implant injury model over both NC stab, scissors stab, and normal animals to correlate with the observed increase in GFAPIR (Table 1).

In a previous report (Moumdjian et al., 1991), we demonstrated that following a large stab wound to the adult rat brain, the extent of astroglial reactivity was extensive and involved also the contralateral hemisphere. In the present study with neonatal mice, no contralateral astrogliosis was documented for any of the injuries performed, including the NC implant group, where ipsilateral astrogliosis was extensive (Figs. 1, 2). Furthermore, when GFAP protein content was quantified from tissue some distance from the lesion site (corresponding contralateral area or ipsilateral areas at least $4 \mathrm{~mm}$ from the lesion), no changes could be documented from controls, even in the NC implant group (data not shown). Thus, while NC implant in neonatal mouse brains resulted in an increase in GFAP-IR (Fig. 1) and GFAP protein content (Fig. 4), this was focal and remained confined to the area immediately circumscribing the lesion.

The above findings of the increased GFAP-IR and GFAP content in the neonatal $\mathrm{NC}$ implant group, but not in the $\mathrm{NC}$ stab or scissors stab animals (Table 1), suggest that the occurrence of astrogliosis in the neonatal brain is clearly feasible and is dependent on the type of injury inflicted.

\section{Cytokines can enhance neonatal astrogliosis}

Qualitative analysis. To assess the contribution of the immune system in producing astrogliosis, we augmented the neonatal's immature immune system with the administration of cytokines. The scissors stab-injured animals with its minimal astrogliosis now demonstrate enhanced GFAP-IR to most cytokines. As shown in Table 2 , recombinant mouse $\gamma$-IFN, IL-1, IL-2, IL-6, TNF- $\alpha$, and M-CSF elicited increased GFAP-IR when compared to vehicle $(0.2 \%$ BSA)-treated controls. In contrast, human $\gamma$-IFN did not evoke astrogliosis over that of vehicle-treat-

\footnotetext{
Figure 1. Implant of NC membrane into P3 mouse pups for $4 \mathrm{~d}$ increases the extent of GFAP-IR at the implant site $(C)$. In $C$, the cortical area occupied by GFAP-IR astrocytes is encompassed within the traced outline. In normal neonates $(A$ and $B$, representing the ipsilateral and contralateral hemispheres), or in the contralateral hemisphere of NC implant pups $(D)$, GFAP-IR was detected only in the corpus callosum (top of each frame) and glia limitans (bottom of each frame). Images in $A-D$ were acquired by confocal laser scanning microscopy (described in detail in Materials and Methods) using a $2.5 \times$ objective. $E$ is a higher magnification of the traced area in $C$, acquired using a $40 \times$ objective, to denote the morphology and reactive nature of the astrocytes.
} 

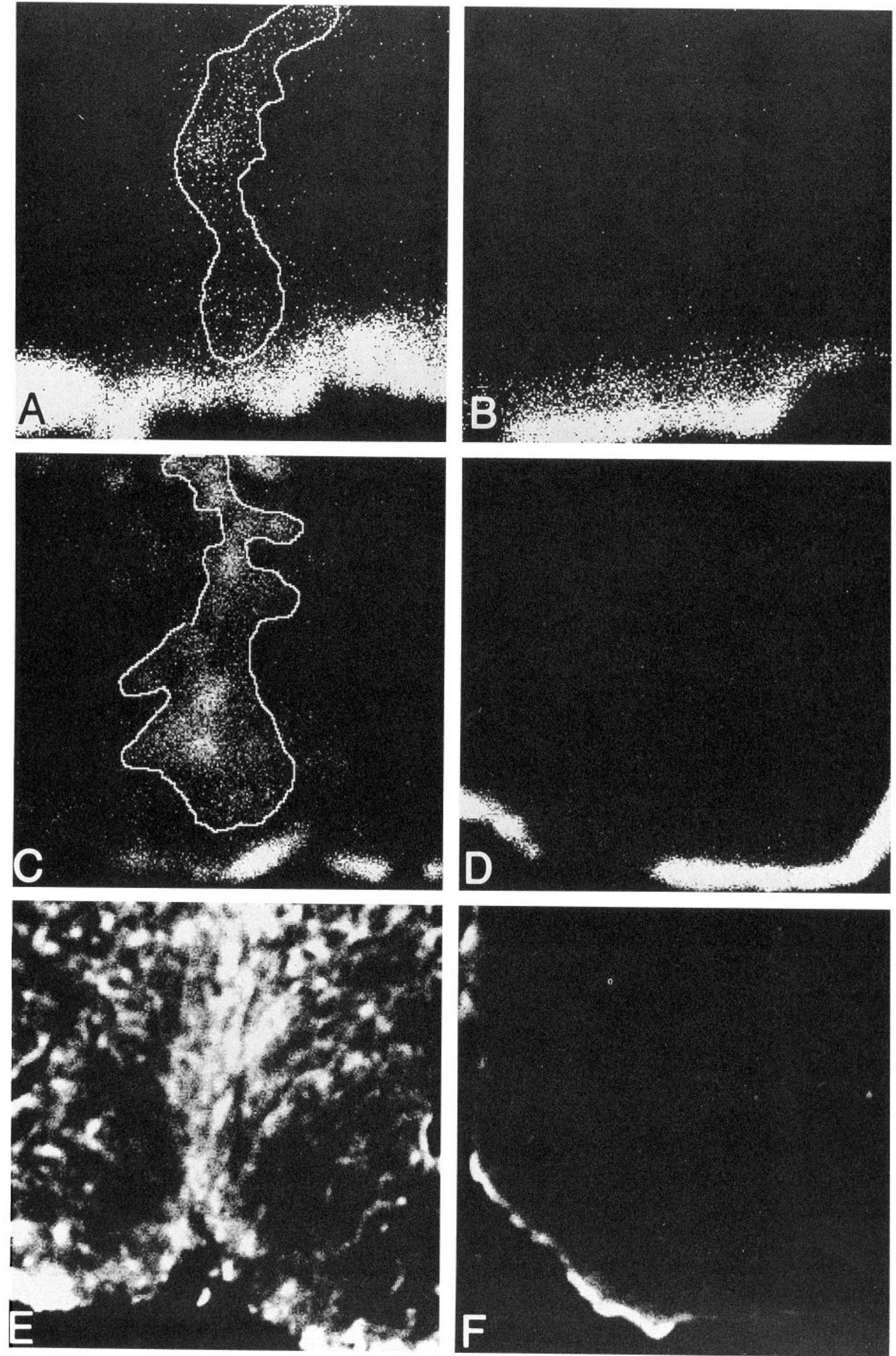
Extent Of GFAP-IR In Neonatal Mouse Brain In Response To Different Injuries

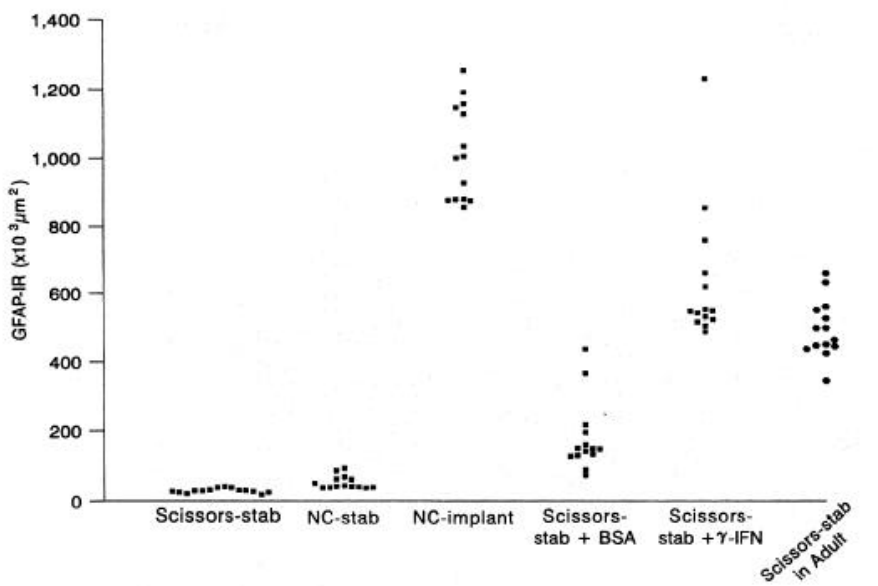

Figure 3. Quantitative comparisons of the cortical area covered by GFAP-IR astrocytes in the different injury paradigms in mouse pups. Injury was inflicted on P3, and animals were killed $4 \mathrm{~d}$ after. Adult scissors stab animals have been included for reference. Each data point represents the image acquired from a single brain section. Two brain sections per animal, taken from the lesion site in all cases, from seven animals per group, were analyzed. Scissors stab (mean GFAP-IR area of $30 \pm 2 \times 10^{3} \mu \mathrm{m}^{2}$ ) or NC stab (mean area of $53 \pm 5 \times 10^{3} \mu \mathrm{m}^{2}$ ) to neonates elicited little astrogliosis when compared to neonate $\mathrm{NC} \mathrm{im-}$ plant (mean area of $1016 \pm 37 \times 10^{3} \mu \mathrm{m}^{2}$ ) or adult scissors stab injuries $\left(496 \pm 22 \times 10^{3} \mu \mathrm{m}^{2}\right)$. The introduction of $2 \mu \mathrm{l}$ of $0.2 \%$ BSA to the neonatal scissors stab wound site resulted in increased GFAP-IR (mean area of $180 \pm 27 \times 10^{3} \mu \mathrm{m}^{2}$ ) compared to scissors stab alone, while 20 $\mathrm{U}$ of $\gamma$-IFN in $0.2 \%$ BSA enhanced astroglial reactivity even further (mean area of $634 \pm 54 \times 10^{3} \mu \mathrm{m}^{2}$ ).

ed controls, in accordance with reports that the interaction of $\gamma$-IFN with its receptor to elicit a response occurs in a speciesspecific manner (Gray et al., 1989; Hemmi et al., 1989; Rubio and de Felipe, 1991; Plata-Salaman, 1992). Vehicle (0.2\% BSA)treated controls displayed moderate astrogliosis, compared to scissors stab-injured animals with minimal astrogliosis (Table 2).

Quantitative analysis. Our choice of cytokine ( $\mathrm{rm} \gamma$-IFN) for quantification of extent of astrogliosis was determined by our long-standing interest in $\gamma$-IFN and its effects on glia (Yong et al., 1991a,b, 1992). The extent of astrogliosis was measured by the density of GFAP-IR cells and the degree of spread of reactivity as one moved away from the wound site (Fig. 5).

Figure 3 shows that the administration of $0.2 \%$ BSA as a vehicle following a scissors stab injury increases the extent of GFAP-IR (mean area of $180 \pm 27 \times 10^{3} \mu \mathrm{m}^{2}$ ) compared to the scissors stab injury alone (mean area of $30 \pm 2 \times 10^{3} \mu \mathrm{m}^{2}$ ). Comparisons between $\mathrm{rm} \gamma$-IFN and its $0.2 \%$ BSA vehicle shows that the deposition of $20 \mathrm{U}$ of $\mathrm{rm} \gamma$-IFN (mean area of $634 \pm$ $\left.54 \times 10^{3} \mu \mathrm{m}^{2}\right)$ further increased the extent of astrogliosis by 3.5 -fold ( $p<0.01$, Student's $t$ test).

Measurements of GFAP content (Fig. 6) of $10 \mathrm{mg}$ samples circumscribing the cytokine-injected scissors stab site show that

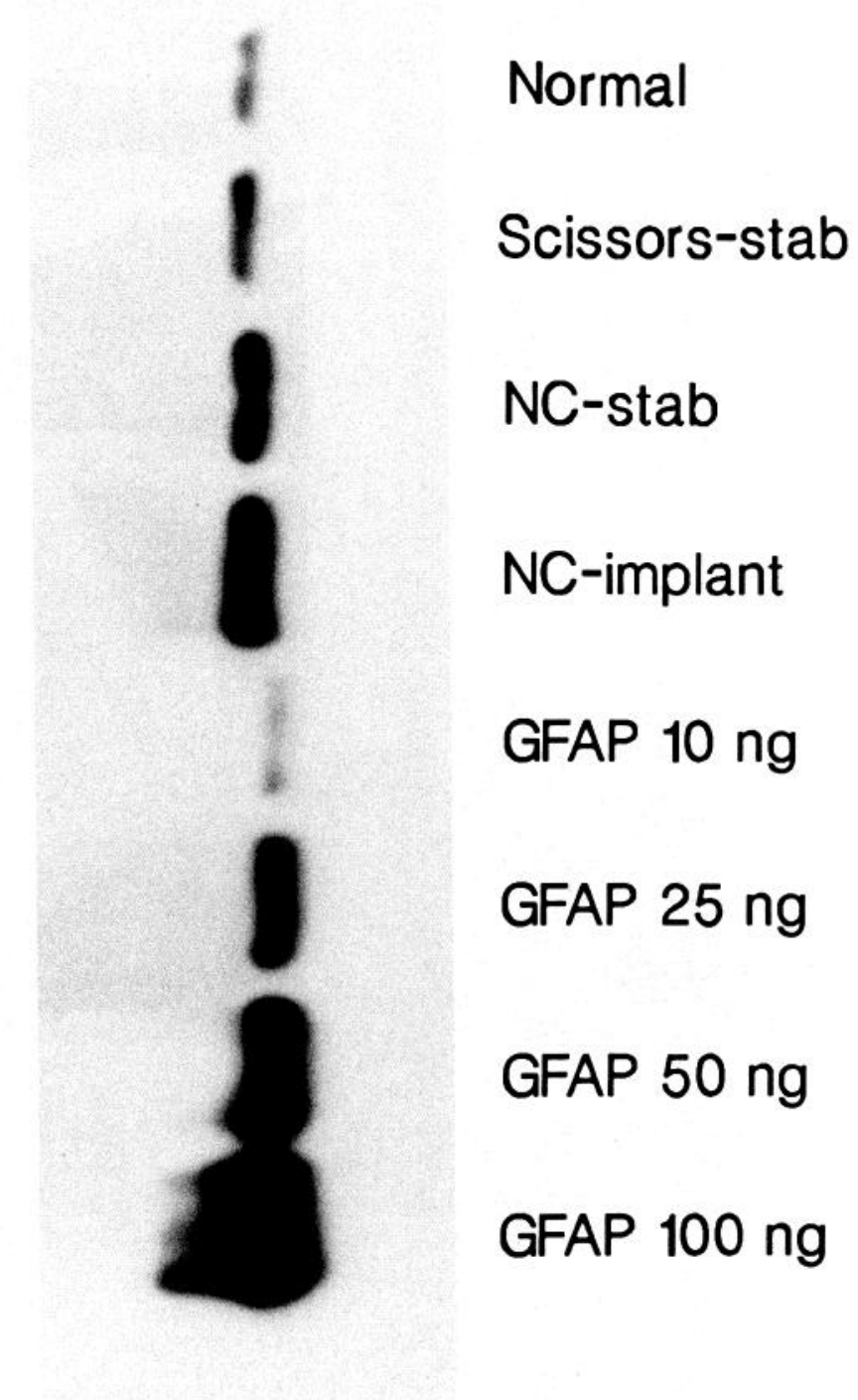

Figure 4. GFAP content of tissues (approximately $10 \mathrm{mg}$ wet weight) circumscribing the lesion site in the different injury paradigms in neonatal animals. GFAP content was read off a standard curve generated by different amounts of purified GFAP (10-100 ng). The mouse GFAP bands ran at a slightly different molecular weight than the GFAP standards $(51 \mathrm{kDa})$ probably because the latter were of bovine extract. GFAP content of normal mouse cortex was $0.3 \mu \mathrm{g} / \mathrm{gm}$ total protein, which corresponds to normal values reported by Goodlett et al. (1993).

when expressed as a ratio of normal brains, GFAP contents for BSA and $\mathrm{rm} \gamma$-IFN groups are, respectively, $2.0 \pm 0.4$ ( $n$ of 8 samples) and $1.9 \pm 0.3$ ( $n$ of 9 samples). Thus, while the GFAP content in tissue circumscribing the injected scissors stab site

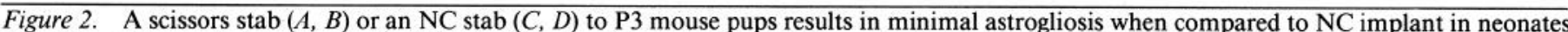

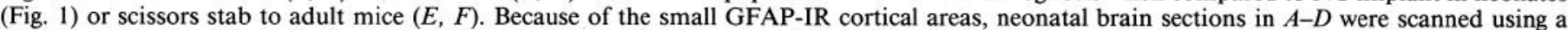

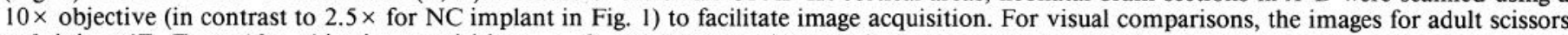

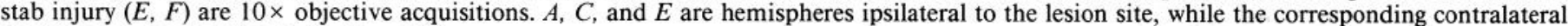
hemispheres are depicted in $B, D$, and $F$. 
Figure 5. Increased GFAP-IR in mouse pups treated with $\operatorname{rm} \gamma$-IFN following a scissors stab wound $(C, D)$ compared to vehicle $(0.2 \% \mathrm{BSA})$ treatment $(A, B) . A$ and $C$ are at the lesion site while $B$ and $D$ are hemispheres contralateral to the lesion. Quantitation of the area of GFAP-IR in each group is displayed in Figure 3; on average, $\mathrm{rm} \gamma$ IFN increased GFAP-IR by 3.5 -fold over its BSA vehicle control.
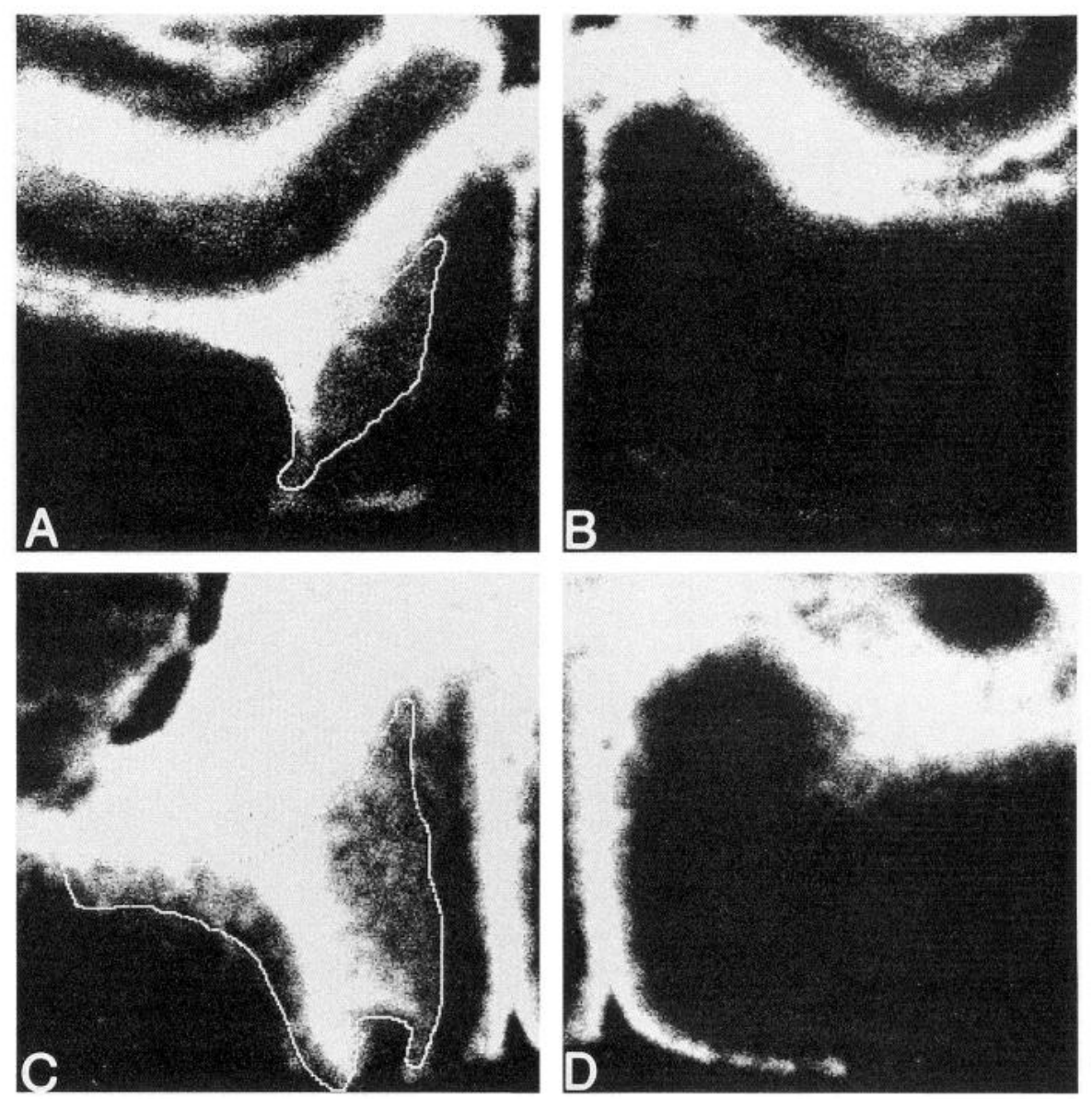

was increased over that of normal brains, $\operatorname{rm} \gamma$-IFN did not elevate GFAP content when compared to its BSA vehicle control. Hence, GFAP content (with no change) does not appear to reflect astrogliosis on the basis of GFAP-IR (3.5-fold increase) following $\mathrm{rm} \gamma$-IFN treatment (Fig. 3).

\section{Proliferative response of neonatal astrocytes to cytokines}

We further addressed the contribution of cytokines toward proliferation of astrocytes, a frequent finding of astrogliosis (Cavanagh, 1970; Latov et al., 1979; Janeczko, 1988, 1991; Takamiya et al., 1988; Topp et al., 1989), by testing for their in

Table 2. Cytokines qualitatively increase the extent of GFAP-IR following neonatal scissors stab injury

\begin{tabular}{lll} 
Treatment & $\begin{array}{l}\text { Number } \\
\text { of mice }\end{array}$ & $\begin{array}{l}\text { Extent of } \\
\text { GFAP-IR }\end{array}$ \\
\hline Scissors stab alone & 2 & + \\
$0.2 \%$ BSA & 4 & ++ \\
Human $\gamma$-IFN & 4 & ++ \\
Mouse $\gamma$-IFN & 6 & ++++ \\
IL- $\alpha, \beta$ & 6 & ++++ \\
IL-2 & 4 & ++++ \\
IL-6 & 6 & ++++ \\
TNF- $\alpha$ & 4 & ++++ \\
M-CSF & 4 & ++++
\end{tabular}

Brain sections were analyzed blind and the extent of GFAP-IR in the ipsilateral cortex tabulated from a scale of + (minimal) to ++++ (extensive). On average, four brain sections per animal were analyzed blind. vitro mitogenic capabilities. ${ }^{3} \mathrm{H}$-thymidine measurements revealed that only rm $\gamma$-IFN and recombinant human IL-1 (rhIL1) could alter proliferation in an antimitotic fashion (Table 3 ). Epidermal growth factor, a noncytokine growth factor that served as a positive control to indicate viability and responsiveness of neonatal murine astrocytes to a defined mitogen, increased the proliferation of neonatal murine astrocytes. Thus, the ability of a cytokine to alter the proliferation of neonatal astrocytes in vitro does not predict its capability in enhancing GFAP-IR in vivo.

\section{Discussion}

The presentation of astrogliosis following injury and inflammation to the adult CNS is a stereotypical occurrence recognized by increased GFAP-IR, a long-standing neuropathological hallmark (Latov et al., 1979; Smith et al., 1983; Mathewson and Berry, 1985; Aquino et al., 1988; Takamiya et al., 1988; Hozumi et al., 1990; Maxwell et al., 1990a; Moumdjian et al., 1991). These studies have highlighted a number of salient features associated with astrogliosis: astrocytic hypertrophy is more prominent and precedes astrocytic hyperplasia, astrocytic hypertrophy can occur in the contralateral cortex or other sites remote from the lesion site, and an increase in GFAP-IR is not necessarily paralleled by an increase in GFAP content. The reactive changes to astrocytes at the site of injury could be accounted for by the evolution of a number of factors related to the injury itself, including neuronal necrosis, mechanical changes in the tissue, ionic changes (Mathewson and Berry, 1985), or perhaps the disruption of the blood-brain barrier with 


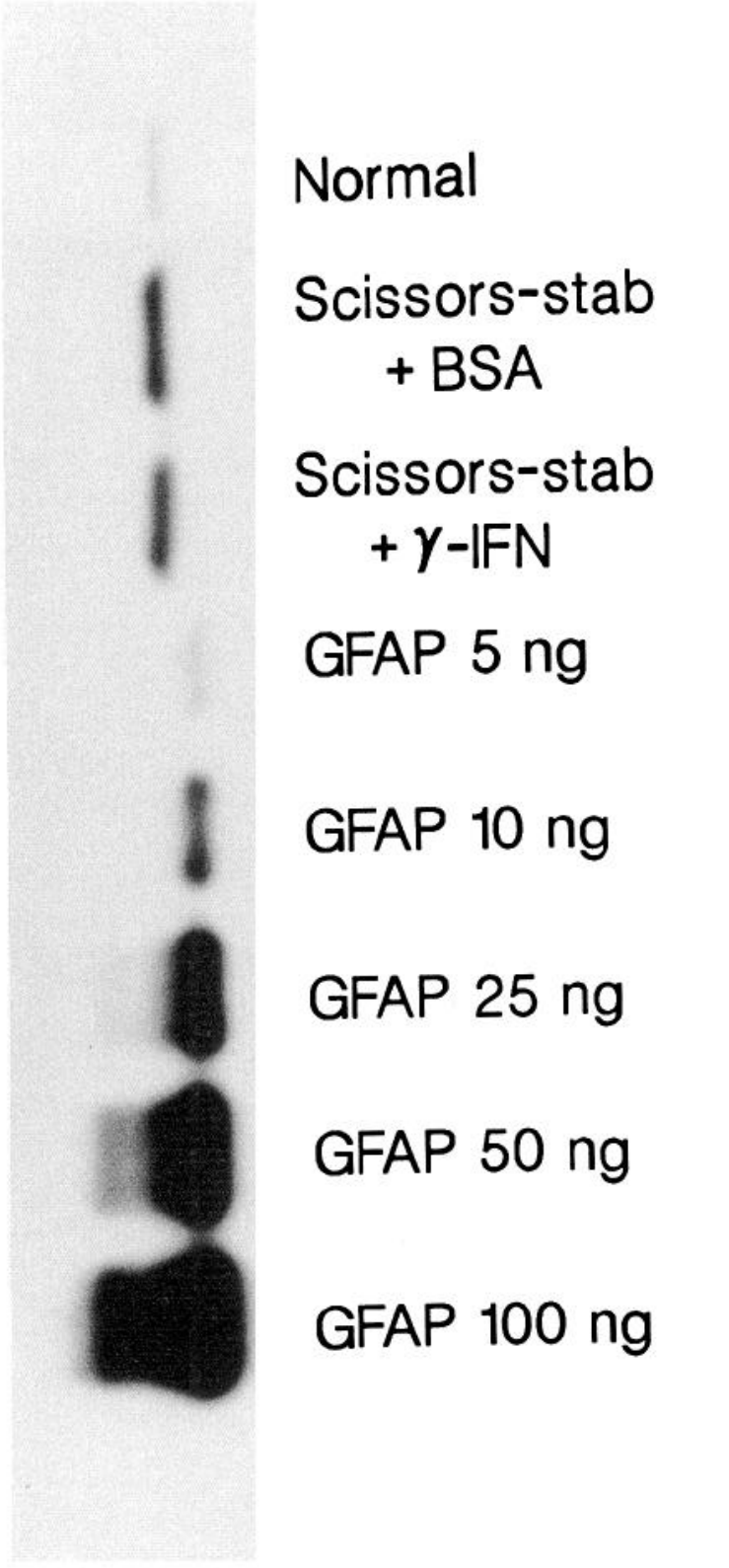

Figure 6. Despite the increase in GFAP-IR elicited by $\gamma$-IFN compared to $0.2 \%$ BSA vehicle, content of GFAP did not differ between the two groups.

consequent migration of inflammatory cells with the potential of cytokine production.

In contrast, the majority of studies have shown that injury to neonatal CNS elicits minimal astrogliosis, if any (Osterberg and Wattenberg, 1963; Sumi and Hager, 1968; Bignami and Dahl, 1976; Gearhart et al., 1979; Bernstein et al., 1981; Berry et al., 1983; Barrett at al., 1984; Maxwell et al., 1990b), although this contention has been challenged (Roessmann and Gambetti, 1986; Moore et al., 1987; Trimmer and Wunderlich, 1990). Possible reasons attributed to the minimal gliotic response in neonatal injury have included the high degree of plasticity within the neonate's relative immature neural environment, and the lack of myelination. Since previous studies have implicated the accumulation of inflammatory mononuclear cells and their cytokines at lesion sites of the CNS in modulating the reactive astrocytic changes (Kitamura et al., 1972; Tsuchihashi et al.,
Table 3. Proliferative response of neonatal mouse astrocytes to cytokines in vitro

\begin{tabular}{llrl} 
Treatment & Concentration & $\begin{array}{l}{ }^{3} \mathrm{H} \text {-thymidine } \\
\text { (\% of controls) }\end{array}$ \\
\hline Control & - & $100 \pm 2(129)$ \\
BSA & $0.2 \%$ & $102 \pm 3(15)$ \\
Mouse $\gamma$-IFN ${ }^{a}$ & $100 \mathrm{U} / \mathrm{ml}$ & $49.8 \pm 3(18)^{*}$ \\
Human $\gamma$-IFN $^{a}$ & $100 \mathrm{U} / \mathrm{ml}$ & $98.8 \pm 4(12)$ \\
IL-1 $\alpha, \beta$ & $1 \mathrm{U} / \mathrm{ml}$ & $85.8 \pm 5(7)$ \\
& $10 \mathrm{U} / \mathrm{ml}$ & $71.0 \pm 3(15)^{*}$ \\
& $100 \mathrm{U} / \mathrm{ml}$ & $78.4 \pm 4(23)^{*}$ \\
& $500 \mathrm{U} / \mathrm{ml}$ & $78.0 \pm 4(12)^{*}$ \\
IL-2 & $10 \mathrm{U} / \mathrm{ml}$ & $97.3 \pm 4(7)$ \\
& $100 \mathrm{U} / \mathrm{ml}$ & $123 \pm 4(16)$ \\
IL-6 & $10 \mathrm{U} / \mathrm{ml}$ & $111 \pm 5(12)$ \\
& $100 \mathrm{U} / \mathrm{ml}$ & $101 \pm 6(12)$ \\
& $500 \mathrm{U} / \mathrm{ml}$ & $94.1 \pm 6(11)$ \\
TNF- $\alpha$ & $1 \mathrm{U} / \mathrm{ml}$ & $117 \pm 7(12)$ \\
& $10 \mathrm{U} / \mathrm{ml}$ & $99.6 \pm 6(15)$ \\
& $100 \mathrm{U} / \mathrm{ml}$ & $90.0 \pm 5(15)$ \\
& $500 \mathrm{U} / \mathrm{ml}$ & $82.2 \pm 6(14)$ \\
M-CSF & $5 \mathrm{CFU} / \mathrm{ml}$ & $98.9 \pm 5(12)$ \\
& $10 \mathrm{CFU} / \mathrm{ml}$ & $96.9 \pm 4(11)$ \\
& $50 \mathrm{CFU} / \mathrm{ml}$ & $111 \pm 3(12)$ \\
EGF & $5 \mathrm{ng} / \mathrm{ml}$ & $323 \pm 34(12)^{*}$ &
\end{tabular}

Results have been compiled from 16 different experiments involving 12 mouse culture series. In all experiments, cells were treated for $4 \mathrm{~d}$ with agents; $1 \mu \mathrm{Ci}$ of ${ }^{3} \mathrm{H}$-thymidine was administered during the last $16 \mathrm{hr}$ of experiment. Values are mean \pm SEM whit number of coverslips analyzed shown in parentheses.

"Confirms published results (Yong et al., 1992) that mouse but not human $\gamma$-IFN produces decrease in proliferation rate at 10,100 , and $1000 \mathrm{U} / \mathrm{ml}$.

"This noncytokine growth factor was used as a positive mitogenic control.

* $p<0.05$ compared to controls (one-way ANOVA with Duncan's multiple comparisons).

1981; Giulian et al., 1987, 1989; Morshead and van der Kooy, 1990, Milligan et al., 1991; Woodroofe et al., 1991; Yong et al., 1991a; Taupin et al., 1993) and given the relative immaturity of the immune system in neonates compared to adults (Hobbs, 1969; Abo et al., 1983; Lu and Unanue, 1985; De Paoli et al., 1988; Hannet et al., 1992), we postulated that the immaturity of the immune system in neonates may contribute to the lack of neonatal astrogliosis. To test this postulate, we sought to evoke astrogliosis in neonatal animals by administering cytokines to the brain following injury.

It was first necessary to document that the neonatal CNS had limited astrogliosis following injury. This was first initiated by implanting a piece of $\mathrm{NC}$ membrane into the P3 mouse brain for $4 \mathrm{~d}$. What was observed, however, was a tremendous GFAPIR (Fig. 1). In contrast, an iris scissors stab wound to the neonatal brain (Fig. 2), similar to the stab models used by others with reports of minimal astrogliosis (Sumi and Hager, 1968; Bignami and Dahl, 1976; Berry et al., 1983; Maxwell et al., 1990b), evoked little GFAP-IR and a small increase in GFAP content (Table 1). The cause of the NC implant in evoking astrogliosis in neonatal animals is probably due to its continued presence in vivo, since in the NC stab animals (injury using an NC membrane, which was then removed immediately), minimal astrogliosis was observed $4 \mathrm{~d}$ later (Fig. 2). It is probable that the continued presence of the NC implant against a background of a maturing immune system provides a sufficient stimulus to evoke an immune cascade; the release of adequate cy- 
tokines at the lesion site may then contribute to the extensive astrogliosis observed (Fig. 3). Whatever the explanation, the conclusion is that reactive astrogliosis as measured by GFAPIR and GFAP content (Fig. 4) can occur in the neonatal brain, and that it is dependent on the type of injury inflicted (Table 1).

In the NC implant model, astrogliosis was characterized by both an increased synthesis of GFAP intermediate filaments and hypertrophy of the astrocytic cytoplasmic processes. The functional role for the increase in this intermediate filament is not known. Smith et al. (1986) have reported that reactive astrocytes could migrate on to an NC implant within 24-48 $\mathrm{hr}$ postimplantation in neonatal animals and that these astrocytes formed a terrain that facilitated axonal extension and regeneration. These neonatal astrocytes also appeared to lack the expression of putative growth-inhibitory molecules such as chondroitin-6-sulfate proteoglycan and cytotactin that were present in adult astrocytes (McKeon et al., 1991). These findings suggest that neonatal reactive astrocytes may have potential regenerative properties.

To test the hypothesis implicating cytokines as contributors toward astrogliosis, we chose to utilize the neonatal stab model with its inherent minimal gliotic response. A single microinjection of cytokines (rm $\gamma$-IFN, rhIL-1, rhIL-2, rhIL-6, rhTNF- $\alpha$, and rhM-CSF, all of which are described to be effective in mouse cells by the manufacturer) into the cerebral cortex of the neonatal mouse produced an astrogliotic response (Table 2), similar to that seen in adult stab wound models by GFAP immunoreactivity (Fig. 2) (Mathewson and Berry, 1985; Moumdjian et al., 1991; Yong et al., 1991a). The specificity of the cytokine effect was demonstrated by the inability of $\operatorname{rh} \gamma$-IFN to evoke an astrogliotic response beyond that of vehicle-treated controls ( $\mathrm{Ta}$ ble 2), an observation that is in accordance with reports indicating a species-specific interaction between $\gamma$-IFN and its receptor (Gray et al., 1989; Hemmi et al., 1989; Rubio and de Felipe, 1991; Plata-Salaman, 1992). The finding that a single administration of cytokines can induce significant astrogliosis in the neonatal stab model with its inherent minimal astrogliosis is consistent with the postulate that the lack of astrogliosis following neonatal injury is related to an immature immune system; this immature immune system would then be reconstituted by cytokine administration.

The quantification of the extent of astrogliosis evoked by $\mathrm{rm} \gamma$ IFN $\left(634 \pm 54 \times 10^{3} \mu \mathrm{m}^{2}\right)$ revealed a 3.5 -fold increase over that of vehicle-treated controls $\left(180 \pm 27 \times 10^{3} \mu \mathrm{m}^{2}\right)$ as determined by GFAP-IR (Figs. 3, 5). However, the analyses of GFAP content from tissue circumscribing the injection sites for $\mathrm{rm} \gamma-$ IFN and vehicle-treated controls did not differ but it was higher than unoperated normal controls (Fig. 6). Thus, GFAP content did not reflect the extent of astrogliosis on the basis of GFAPIR following $\mathrm{rm} \gamma$-IFN treatment. A similar type of occurrence has been documented in animals with experimental autoimmune encephalomyelitis (EAE), where GFAP content of the spinal cord did not differ from controls at 13-18 d postinoculation (dpi), a period when intense GFAP-IR was observed in the EAE groups (Smith et al., 1983; Goldmuntz et al., 1986); correlation of GFAP-IR with GFAP content was observed at later periods (35-65 dpi) (Aquino et al., 1988). The most likely interpretation for the noncorrespondence between GFAP-IR and GFAP content may be that as astrocytes swell and GFAP filament dissociate there is an increased availability of antigenic epitopes to antibodies for GFAP (Aquino ct al., 1988; Eng ct al., 1989). This phenomenon seen in EAE for the initial increase in GFAP-IR before eventual increase in GFAP content appears similar to that observed in our neonatal $\mathrm{rm} \gamma$-IFN scissors stab model.

Why do all cytokines tested induce astrogliosis? While it is possible that all these cytokines have direct effects on astrocytes, an indirect phenomenon through a possible common pathway is also likely. This route may conceivably be by the recruitment of inflammatory mononuclear cells, including a final effector cell and its cytokine(s), to the lesion site. This possibility is supported by the report of Brosnan et al. (1989), who described the occurrence of astrogliosis and increased adherence of inflammatory cells to the vasculature after intraocular injection of $\gamma$-IFN, TNF- $\alpha$, and IL-1. In addition, Watts et al. (1989) have demonstrated the disruption of the blood-brain barrier and the recruitment of inflammatory cells to the intracerebral injection site of IL-2. Furthermore, Simmons and Willenbourg (1990) have described the occurrence of a widespread inflammatory response to a single microinjection of $\gamma-\mathrm{IFN}$ or TNF- $\alpha$ in the lumbosacral cord. Finally, Sethna and Lampson (1991) have observed a that a single intracerebral injection of $\gamma$-IFN resulted in the recruitment of many types of inflammatory cells to the brain. Our laboratory is currently testing the direct and indirect role of cytokines in mediating gliosis in vivo. We are examining the role of $\gamma$-IFN as a final common mediator, given the identification of a specific receptor for mouse $\gamma$-IFN on neonatal mouse astrocytes (Rubio and de Felipe, 1991), and given the potent effects of $\gamma$-IFN on astrocytes in mixed or purified cultures in vitro (Yong et al., 1991a,b, 1992).

An important question now arises: which cells are responsible for the production of cytokines? Conceivably, infiltrating mononuclear phagocytes (macrophages) and other cells of the immune system (e.g., T-lymphocytes and NK cells) are potentially involved. Cells intrinsic to the CNS could also be potential sources of cytokines. In this regard, microglia, astrocytes, and even neurons have been suggested to synthesize cytokines under selective conditions (Giulian et al., 1987; Wesselingh et al., 1990; Logan et al., 1992; Tchelingerian et al., 1993). The nature of the in vivo cellular elements contributing to cytokine(s) production following injury remains to be elucidated.

Our investigations demonstrate that the ability of a cytokine to alter the proliferation of neonatal astrocytes in vitro does not predict its capability in enhancing GFAP-IR in vivo. While all cytokines tested in vivo increased GFAP-IR (Table 2), our in vitro studies implicate an antimitotic effect by $\operatorname{rm} \gamma$-IFN (Yong et al., 1992) and IL-1, without any significant effects by the other cytokines (Table 3 ). It is also worth noting that while others have found II -1, IL- 6 , and TNF- $\alpha$ to be mitogenic for neonatal rat and calf bovine astrocytes (Giulian and Lachman, 1985; Nieto-Sampedro and Berman, 1987; Selmaj et al., 1990), these cytokines were not mitogenic for neonatal mouse astrocytes. This apparent discrepancy may be due to species differences, since we have demonstrated that while $\operatorname{rm} \gamma$-IFN was inhibitory for proliferation of neonatal or adult mouse astrocytes, $\operatorname{rh} \gamma$-IFN was a mitogen for fetal and adult human astrocytes (Yong et al., 1992).

In conclusion, astrogliosis can occur in the neonatal brain if a sufficient stimulus (NC implant) is present. For the neonatal scissors stab wound model with its inherent minimal astrogliosis, a single administration of cytokines induces extensive astrogliosis. These results implicate immunoregulatory cytokines as important contributing factors to the production of astrogliosis following an injury to the CNS. 


\section{References}

Abo T, Miller CA, Gartland GL, Balch CM (1983) Differentiation stages of human natural killer cells in lymphoid tissue from fetal to adult life. J Exp Med 157:273-284.

Aquino DA, Chiu FC, Brosnan CF, Norton WT (1988) Glial fibrillary acidic protein increases in the spinal cord of Lewis rats with acute experimental autoimmune encephalomyelitis. J Neurochem 51:10851096.

Barna BP, Estes ML, Jacobs BS, Hudson S, Ransohoff RM (1990) Human astrocytes proliferate in response to tumor necrosis factor alpha. J Neuroimmunol 30:239-243.

Barrett CP, Donati EJ, Guth L (1984) Differences between adult and neonatal rats in their astroglial response to spinal injury. Exp Neurol $84: 374-385$.

Bernstein DR, Bechard DE, Stelzner DJ (1981) Neurite growth maintained near the lesion site long after spinal cord transection in the newborn rat. Neurosci Lett 26:55-60.

Berry M, Maxwell WL, Logan A, Mathewson A, McConnell P, Ashburst DE, Thomas GH (1983) Deposition of scar tissue in the central nervous system. Acta Neurochir [Suppl] 32:31-53.

Bignami A, Dahl D (1974) Astrocyte-specific protein and neuroglial differentiation. An immunofluorescence study with antibodies to the glial fibrillary acidic protein. J Comp Neurol 153:27-38.

Bignami A, Dahl D (1976) The astroglial response to stabbing: immunofluorescence studies with antibodies to astrocyte-specific protein (GFA) in mammalian and submammalian vertebrates. Neuropathol Appl Neurobiol 2:99-1 10.

Brosnan CF, Litwak MS, Schroeder CE, Selmaj K, Raine CS, Arezzo JC (1989) Preliminary studies of cytokine-induced functional effects on the visual pathways in the rabbit. J Neuroimmunol 25:227-239.

Cavanagh JB (1970) The proliferation of astrocytes around a needle wound in the rat brain. J Anat 106:471-487.

De Paoli P, Battistin S, Santini GF (1988) Age-related changes in human lymphocyte subsets: progressive reduction of the CD4 CD45R (suppressor inducer) population. Clin Immunol Immunopathol 48: 290-296.

Eng LF (1985) Glial fibrillary acidic protein (GFAP): the major protein of glial intermediate filaments in differentiated astrocytes. J Neuroimmunol 8:203-2I4.

Eng LF, D'Amelio FE, Smith ME (1989) Dissociation of GFAP intermediate filaments in EAE: observations in the lumbar spinal cord. Glia 2:308-317.

Gearhart J, Oster-Granite ML, Guth L (1979) Histological changes after transection of the spinal cord of fetal and neonatal mice. Exp Neurol 66:1-15.

Giulian D (1987) Ameboid microglia as effectors of inflammation in the central nervous system. J Neurosci Res 18:155-171.

Giulian D, Lachman LB (1985) Interleukin-1 stimulation of astroglia proliferation after brain injury. Science 228:497-499.

Giulian D, Wondward J, Young DF, Krebs JF, Lachman LB (1988) Interleukin 1 injected into mammalian brain stimulates astrogliosis and neovascularization. J Neurosci 8:2485-2490.

Giulian D, Chen J, Ingeman JE, George JK, Noponen M (1989) The role of mononuclear phagocytes in wound healing after traumatic injury to the adult mammalian brain. J Neurosci 9:4416-4429.

Goldmunt $\angle$ EA, Brosnan CF, Chiu FC, Norton WT (1986) Astrocytic reactivity and intermediate filament metabolism in experimental autoimmune encephalomyelitis: the effect of suppression with prazosin. Brain Res 397:16-26.

Goodlett CR, Leo JT, O'Callaghan JP, Mahoney JC, West JR (1993) Transient cortical astrogliosis induced by alcohol exposure during the neonatal brain growth spurt in rats. Dev Brain Res 72:85-97.

Gray PW, Leong S, Fennie EH, Farrar MA, Pingel JT, Fernandez-Luna I, Schreiber RD (1989) Cloning and expression of the cDNA for the murine interferon $-\gamma$ receptor. Proc Natl Acad Sci USA 86:84978501.

Hannet I, Erkeller-Yuksel F, Lydyard P, Deneys V, DeBruyere M (1992) Developmental and maturational changes in human blood lymphocyte subpopulations. Immunol Today 13:215-218.

Hemmi S, Peghini P, Metzler M, Merlin G, Dembic Z, Aguet M (1989) Cloning of murine interferon $-\gamma$ receptor CDNA: expression in human cells mediates high affinity binding but is not sufficient to confer sensitivity to murine interferon- $\gamma$. Proc Natl Sci Acad USA 86:99019905.
Hobbs JR (1969) Primary immune paresis. In: Immunology and development (Adinolfi M, ed), pp 117-118. London: Heinemann.

Hozumi I, Chiu FC, Norton WT (1990) Biochemical and immunocytochemical changes in glial fibrillary acidic protein after stab wounds. Brain Res 524:64-71.

Kitamura T, Hattori H, Fujita S (1972) Autoradiographic studies of histogenesis of brain macrophages in the mouse. J Neuropathol Exp Neurol 31:502-518

Janeczko K (1988) The proliferative response of astrocytes to injury in neonatal rat brain. A combined immunocytochemical and autoradiographic study. Brain Res 456:280-285.

Janeczko K (1991) The proliferative response of S-100 protein positive glial cells to injury in the neonatal rat brain. Brain Res 564:86-90,

Latov N, Nilaver G, Zimmerman EA, Johnson WG, Silverman AJ, Defendini R, Cote L (1979) Fibrillary astrocytes proliferate in response to brain injury. Dev Biol 72:381-384.

Liuzzi FJ, Lasek RJ (1987) Astrocytes block axonal regeneration in mammals by activating the physiological stop pathway. Science 237 : 642-645.

Logan A, Frautschy SA, Gonzalez A-M, Sporn MB, Baird A (1992) Enhanced expression of transforming growth factor $\beta 1$ in the rat brain after a localized cerebral injury. Brain Res 587:216-225.

Lu CY, Unanue ER (1985) MAcrophage ontogeny: implications for host defense, T-lymphocyte differentiation, and the acquisition of self tolerance. Clin Immunol Allergy 5:253-269.

Mathewson AJ, Berry M (1985) Observations on the astrocyte response to a cerebral stab wound in adult rats. Brain Res 327:61-69.

Maxwell WL, Follows R, Ashhurst DE, Berry M (1990a) The response of the cerebral hemisphere of the rat to injury. I. The mature rat. Philos Trans R Soc Lond [Biol] 328:479-500.

Maxwell WL, Follows R, Ashhurst DE, Berry M (1990b) The response of the cerebral hemisphere of the rat to injury. II. The neonatal rat. Philos Trans R Soc Lond [Biol] 328:501-513.

McKeon RJ, Schreiber RC, Rudge JS, Silver J (1991) Reduction of neurite outgrowth in a model of glial scarring following CNS injury is correlated with the expression of inhibitory molecules on reactive astrocytes. J Neurosci 11:3398-3411.

Milligan CE, Levitt P, Cunningham TJ (1991) Brain macrophages and microglia respond differently to lesions of the developing and adult visual system. J Comp Neurol 314:136-146.

Moore IE, Bountempo JM, Weller RO (1987) Response of fetal and neonatal rat brain to injury. Neuropathol Appl Neurobiol 13:219228

Morshead CM, van der Kooy D (1990) Separate blood and brain origins of proliferating cells during gliosis in adult brains. Brain Res 535:237-244.

Moumdjian R, Antel JP, Yong VW (1991) Origin of contralateral reactive gliosis in surgically injured rat cerebral cortex. Brain Res 547: 223-228.

Nieto-Sampedro M, Berman MA (1987) Interleukin-1 like activity in rat brain: sources, targets, and effect of injury. J Neurosci Res 17 : 214-219.

Norton WT, Aquino DA, Hozumi I, Chiu FC, Brosnan CF (1992) Quantitative aspects of reactive gliosis: a review. Neurochem Res 17 877-885.

Osterberg KA, Wattenberg LW (1963) The age of dependency of enzymes in reactive glia. Proc Soc Exp Biol Med 113:145-147.

Plata-Salaman CR (1992) Interferon and central regulation of feeding. Am J Physiol 263:R1222-R1227.

Reier PJ, Stensaas LJ, Guth L (1983) The astrocytic scar as an impediment to regeneration in the central nervous system. In: Fundamentals of spinal cord reconstruction (Kao CC, Bunge RP, Reier PJ, cds), p 163. New York: Raven.

Roessmann U, Gambetti P (1986) Pathological reaction of astrocytes in perinatal brain injury. Acta Neuropathol (Berl) 70:302-307.

Rubio N, de Felipe C (1991) Demonstration of the presence of a specific interferon- $\gamma$ receptor on murine astrocyte cell surface. J Neuroimmunol 35:111-117.

Rudge JS, Smith GM, Silver J (1989) An in vitro model of wound healing in the CNS: analysis of cell reaction and interaction at different ages. Exp Neurol 103:1-16.

Selmaj KW, Farooq M, Norton WT, Raine CS, Brosnan CF (1990) Proliferation of astrocytes in vitro in response to cytokines: a primary role of tumor necrosis factor. J Immunol 144:129-135.

Sethna MP, Lampson LA (1991) Immune modulation within the brain: 
recruitment of inflammatory cells and increased major histocompatibility antigen expression following intracerebral injection of interferon- $\gamma$. J Neuroimmunol 34:121-132.

Simmons RD, Willenborg Do (1990) Direct injection of cytokines into the spinal cord causes autoimmune encephalomyelitis-like inflammation. J Neurol Sci 100:37-42.

Smith GM, Miller RH, Silver J (1986) Changing role of forebrain astrocytes during development, regenerative failure, and induced regeneration upon transplantation. J Comp Neurol 251:23-43.

Smith ME, Eng L (1987) Glial fibrillary acidic protein in chronic relapsing experimental allergic encephalomyelitis in $\mathrm{SJL} / \mathrm{J}$ mice. $\mathrm{J}$ Neurosci Res 18:203-208.

Smith ME, Somera FP, Eng L (1983) Immunocytochemical staining for glial fibrillary acidic protein and the metabolism of cytoskeletal proteins in experimental allergic encephalomyelitis. Brain Res 264: 241-253.

Sumi SM, Hager H (1968) Electron microscopic study of the reaction of the newhorn rat brain to injury. Acta Neuropathol (Berl) 10:324335.

Takamiya Y, Kohsaka S, Toya S, Otani M, Tsukada Y (1988) Immunohistochemical studies on the proliferation of reactive astrocytes and the expression of cytoskeletal proteins following brain injury in rats. Dev Brain Res 38:201-210.

Taupin V, Toulmond S, Serrano A, Benavides J, Zavala F (1993) Increase in IL-6, IL-1 and TNF levels in rat brain following traumatic lesion. J Neuroimmunol 42:177-186.

Tchelingerian J-L, Quinonero J, Booss J, Jacque C (1993) Localization of TNF $\alpha$ and IL- $1 \alpha$ immunoreactivities in striatal neurons after surgical injury to the hippocampus. Neuron 10:213-224.

Topp KS, Faddis BT, Vijayan VK (1989) Trauma-induced proliferation of astrocytes in the brains of young and aged rats. Glia 2:201211 .
Trimmer PA, Wunderlich RE (1990) Changes in astroglial scar formation in rat optic nerve as a function of development. J Comp Neurol 296:359-378.

Tsuchihashi Y, Kitamura T, Fujita S (1981) Immunofluorescence studies of the monocytes in the injured rat brain. Acta Neuropathol (Berl) 53:213-219.

Watts RG, Wright JL, Atkinson LL, Merchant RE (1989) Histopathological and blood-brain barrier changes in rats induced by an intracerebral injection of human recombinant interleukin-2. Neurosurgery 25:202-208

Wesselingh SL, Gough NM, Finlay-Jones JJ, McDonald PJ (1990) Detection of cytokine MRNA in astrocyte cultures using the polymerase chain reaction. Lymphokine Res 9:177-185.

Woodroofe MN, Sarna GS, Wadhwa M, Hayes GM, Loughlin AJ, Tinker A, Cuzner ML (1991) Detection of interleukin-1 and interleukin-6 in adult rat brain, following mechanical injury, by in vivo microdialysis: evidence of a role for microglia in cytokine production. J Neuroimmunol 33:227-236.

Yong VW (1992) Proliferation of human and mouse astrocytes in vitro: signalling through the protein kinase C pathway. J Neurol Sci 111:92-103.

Yong VW, Moumdjian R, Yong FP, Ruijs TCG, Freedman MS, Cashman N, Antel JP (1991a) Gamma-interferon promotes proliferation of adult human astrocytes in vitro and reactive gliosis in the adult mouse brain in vivo. Proc Natl Acad Sci USA 88:7016-7020.

Yong VW, Yong FP, Ruijs TCG, Antel JP, Kim SU (1991b) Expression and modulation of HLA-DR on cultured human adult astrocytes. J Neuropathol Exp Neurol 50:16-28.

Yong VW, Tejada-Berges T, Goodyer CG, Antel JP, Yong FP (1992) Differential proliferative response of human and mouse astrocytes to gamma-interferon. Glia 6:269-280. 